\title{
Diffusion capacity and haemodynamics in primary and chronic thromboembolic pulmonary hypertension
}

\author{
L.H. Steenhuis, H.J.M. Groen, G.H. Koëter, Th W. van der Mark
}

\begin{abstract}
Diffusion capacity and haemodynamics in primary and chronic thromboembolic pulmonary hypertension. L.H. Steenhuis, H.J.M Groen, G.H. Koëter, Th. W. van der Mark. (C) ERS Journals Ltd 2000.

ABSTRACT: The transfer factor of the lung for carbon monoxide $(T \mathrm{~L}, \mathrm{CO})$ is decreased in patients with pulmonary hypertension. The pulmonary membrane diffusion capacity $(D \mathrm{~m})$ and pulmonary capillary blood volume $(V \mathrm{c})$, were studied to establish: 1) the relative contribution of the components of the transfer factor to the decrease in $T L, C O ; 2)$ whether differences exist between primary pulmonary hypertension (PPH) and chronic thromboembolic pulmonary hypertension (CTEPH); and 3) the relationship between these parameters and haemodynamic parameters.

$D_{m}$ and $V_{c}$ were determined in 19 patients with PPH and in eight patients with CTEPH. The patients had been referred for consideration for lung transplantation. Haemodynamic parameters were assessed by heart catheterization.

In the PPH group, $V_{c}$ was reduced in 12 of 19 patients (mean $\pm S D V_{c} 72 \pm 14 \%$ of the predicted value) and $D \mathrm{~m}$ in 17 of 19 patients $\left(60 \pm 22 \%\right.$ pred). In the CTEPH group, $V_{\mathrm{c}}$ was reduced in six of eight patients and $D \mathrm{~m}$ in seven of eight patients. The mean $T \mathrm{~L}, \mathrm{CO}$ $D \mathrm{~m}$ and $V_{\mathrm{c}}$ values were similar to those in the PPH group.

The reduction in pulmonary membrane diffusion capacity was significantly greater than that in pulmonary capillary blood volume. No differences in pulmonary and cardiovascular functional values were found between the groups. Right atrial pressure showed a significant negative correlation with pulmonary capillary blood volume and an increased pulmonary vascular resistance was associated with a decrease in pulmonary membrane diffusion capacity. These results suggest pronounced functional impairment of the alveolocapillary membrane in these patients.

Eur Respir J 2000; 16: 276-281.
\end{abstract}

Dept of Pulmonary Diseases, University Hospital Groningen, Groningen, the Netherlands.

Correspondence: Th.W. van der Mark

Dept of Pulmonary Diseases

University Hospital Groningen

P.O. Box 30001

9700 RB Groningen

the Netherlands

Fax: 31503619320

Keywords: Cardiovascular function pulmonary hypertension

transfer factor

Received: September 101999

Accepted after revision April 202000

Primary pulmonary hypertension $(\mathrm{PPH})$ is a severe lifethreatening disease with an estimated incidence of 1-2 cases per million people in the general population $[1,2]$. It is characterized by progressive elevation of pulmonary arterial pressure and diagnosed by exclusion of known causes of pulmonary hypertension. Morphologically this disease can be classified into three histopathological patterns: plexogenic pulmonary arteriopathy; thrombotic pulmonary arteriopathy; and veno-occlusive disease [3]. Plexogenic arteriopathy is characterized by an increase in both the size and number of smooth muscle cells of the arterial vascular tree, resulting in medial hypertrophy and expansion of the muscular layer to the originally medialess arterioles, leading to so-called muscularization of these arterioles, and, finally, intimal fibrosis, resulting in obliteration of the vascular lumen [4]. The plexogenic form occurs in $28-80 \%$ of cases of PPH [5, 6], and is also found in patients with chronic thromboembolic pulmonary hypertension (CT-EPH) [7]. Generally, PPH has a poor prognosis with a median survival of 3-4 yrs from the time of diagnosis $[8,9]$.

In PPH, a mild restrictive lung function pattern without airway obstruction has been observed [3, 10]. However, BURKE et al. [11] found evidence of airway obstruction primarily affecting the peripheral airways in most pa- tients. Generally, a gas exchange impairment exists in PPH patients with hypoxaemia and hypocapnia. The transfer factor of the lung for carbon monoxide $(T \mathrm{~L}, \mathrm{CO})$ is generally reduced to $\sim 70 \%$ of the predicted value $[8,11]$. No association between TL,CO and the severity of PPH has been found [10].

In CTEPH, a reduction in $T \mathrm{~L}, \mathrm{CO}$ has been described $[12$, 13]. In patients with CTEPH, BERNSTEIN et al. [13] observed a reduction in $T \mathrm{~L}, \mathrm{CO}$, caused by a reduction in pulmonary membrane diffusion capacity $(D \mathrm{~m})$ and, to a lesser extent, a reduction in pulmonary capillary blood volume $\left(V_{\mathrm{c}}\right)$.

The reason for the reduction in TL,CO in patients with PPH is unknown. There is a possibility that it is caused by obliteration of the small pulmonary arteries [14]. Recent studies have shown an important role of endothelial cells in the development of plexiform lesions, leading to vascular obliteration and pulmonary membrane thickening $[5,15,16]$.

$D \mathrm{~m}$ and $V_{\mathrm{c}}$, both components of $T \mathrm{~L}, \mathrm{CO}$ were studied in 20 consecutive patients with PPH and eight consecutive patients with CTEPH in order to establish the relative contribution of the components of the transfer factor to the decrease in $T \mathrm{~L}, \mathrm{CO}$. It was investigated whether it was possible to differentiate between PPH and CTEPH by TL,CO, 
$D \mathrm{~m}$ or $V_{\mathrm{c}}$. Furthermore, the possible relationship between these parameters and haemodynamic variables assessed during right heart catheterization was studied.

\section{Material and methods}

\section{Patients}

Between 1990 and March 1997, 700 patients were referred to Groningen University Hospital because of various end-stage lung diseases to be considered for lung transplantation. Patients were extensively examined, including right heart catheterization and pulmonary function tests. Because of the clinical conditions of some of the patients, not all parameters could be determined in every patient. $\mathrm{PPH}$ was defined as a mean pulmonary arterial pressure (PAP) of $>25 \mathrm{mmHg}$ at rest, or $>30 \mathrm{mmHg}$ with exercise, and by excluding secondary causes of pulmonary hypertension, such as left-sided cardiac valvular disease, myocardial disease, congenital heart disease including septal defects, connective tissue disease, chronic thromboembolic disease and severe chronic obstructive pulmonary disease.

CTEPH was defined as pulmonary hypertension caused by pulmonary embolism as demonstrated angiographically by an abrupt vessel cut-off or a convex vascular filling defect.

\section{Pulmonary function tests}

Total lung capacity (TLC) was determined by the closedcircuit helium-dilution method. Flow/volume curves were constructed via pneumotachography, according to European Community for Coal and Steel (ECCS) guidelines. ECCS reference values were used for pulmonary function tests [17]. When necessary, the recommended correction for non-Caucasians was used. TL,CO, $V_{\mathrm{c}}$ and $D \mathrm{~m}$ were determined from triplicate measurements of $T \mathrm{~L}, \mathrm{CO}$ at high $(88 \%)$ and low $(19.2 \%)$ oxygen concentrations, using the single-breath technique of $\mathrm{M}$. Krogh, as modified by COTES [18]. For calculation of $D \mathrm{~m}$ and $V_{\mathrm{c}}$, the equation of Roughton and Forster [19] was used. This method has been shown to be successful in helping to understand the influence of a number of diseases upon the lung [20-22]. $T \mathrm{~L}, \mathrm{CO}$ values were corrected for haemoglobin concentrations according to COTES [18]. The transfer coefficient was calculated by dividing the $T \mathrm{~L}, \mathrm{CO}$ by the alveolar volume. Predicted values were taken from Cotes [18]. A value of $<80 \%$ pred was considered abnormal. All pulmonary function tests were performed with the patient in a steady-state condition.

\section{Cardiovascular function tests}

Haemodynamic tests were performed within a few days after the pulmonary function tests and consisted of catheterization of the right heart using the Seldinger technique via the femoral vein. Right atrial pressure (RAP) and systolic (SAP) and diastolic pulmonary pressures (DAP) were directly measured by use of a pressure transducer in the tip of the Swan-Ganz catheter. Cardiac output (CO) was measured by the thermodilution method. Calculated parameters were mean PAP, pulmonary vascular resistance (PVR) and cardiac index. Patients used supplemental oxygen when necessary.

\section{Statistics}

Pulmonary function test results were compared to the $80 \%$ pred by use of the one-sample t-test. Differences between groups were evaluated using the independent sample t-test and differences between decreases in pulmonary function parameters with a paired t-test. The relationship between haemodynamic parameters (RAP and PVR) and $T$ L,CO and its components $D \mathrm{~m}$ or $V_{\mathrm{c}}$ was determined using the Pearson correlation coefficient. In cases of nonlinear correlation, a nonparametric test (Spearman rho) was used. A p-value of $<0.05$ was considered significant.

\section{Results}

\section{Patients}

Sixty-three of 700 patients referred to the authors' hospital for lung transplantation assessment matched the criteria of PPH. Due to the various stages of the programme for lung transplantation, only 22 patients were evaluated using pulmonary function tests and right heart catheterization. One patient with ventricular septum defect diagnosed during lung transplantation and one child with $\mathrm{PPH}$ were excluded. One patient refused the second determination of $D$ m, leaving 20 patients in whom $T$ L,CO was determined and 19 patients in whom $D \mathrm{~m}$ and $V_{\mathrm{c}}$ were measured. Patient characteristics are shown in table 1 . In the present study population, the female predominance in PPH was more pronounced compared to other studies $[2,10,11]$. Of the nine patients referred with CTEPH, seven were fully evaluated. In one patient no reliable diffusion tests could be performed, and, in one patient, no right heart catheterization was performed; elevated pulmonary pressure was estimated by Doppler echo cardiography.

\section{Pulmonary function}

In all 29 patients, spirometric values were obtained. The mean TLC was within normal limits. No airway obstruction was found, except in one patient with PPH in whom a significant obstruction was observed with a ratio of forced expiratory volume in one second to vital capacity of $62 \%$. In 17 of $20 \mathrm{PPH}$ patients $T \mathrm{~L}, \mathrm{CO}$ were reduced to $<80 \%$ pred, with mean \pm SD values of $64 \pm 17 \%$ pred. $V$ c was reduced in 12 of 19 patients, with a mean of $72 \pm 14 \%$ pred. $D$ m showed a more pronounced reduction: 17 of 19 patients had reduced $D \mathrm{~m}$, with a mean of $60 \pm 22 \%$ pred.

Table 1. - Patient characteristics

\begin{tabular}{lcc}
\hline & PPH & CTEPH \\
\hline Patients $\mathrm{n}$ & 20 & 9 \\
Male/female & $5 / 15$ & $6 / 3$ \\
Age yrs & $33(20-54)$ & $43(23-60)$ \\
Weight kg & $67(50-90)$ & $71(50-95)$ \\
Height cm & $168(152-193)$ & $178(162-196)$ \\
\hline
\end{tabular}

Data are presented as median (range). PPH: primary pulmonary hypertension; CTEPH: chronic thromboembolic pulmonary hypertension. 
In the CTEPH group, $T \mathrm{~L}, \mathrm{CO}$ was reduced in seven of eight patients, $V_{\mathrm{c}}$ in six of eight and $D \mathrm{~m}$ in seven of eight. $T \mathrm{~L}, \mathrm{CO}, V_{\mathrm{c}}$ and $D \mathrm{~m}$ were all reduced to similar values to those in the PPH group (table 2). No significant difference in $T \mathrm{~L}, \mathrm{CO}, D \mathrm{~m}$ and $V_{\mathrm{c}}$ was obtained between the two groups.

In view of these results, the values for both groups were pooled and tested against a value of $80 \%$ pred using the one-sample t-test. Mean \pm SD values were: $T \mathrm{~L}, \mathrm{CO}, 65 \pm 18 \%$ pred $(\mathrm{p}<0.001) ; V_{\mathrm{c}}, 71 \pm 14 \%$ pred $(\mathrm{p}=0.002)$; and $D \mathrm{~m}$, $62 \pm 23 \%$ pred $(\mathrm{p}<0.001)$. The decrease in $D \mathrm{~m}$ was significantly greater than that in $V_{\mathrm{c}}$ (paired t-test, $\mathrm{p}=0.024$ ).

\section{Cardiovascular function}

RAP was measured in 16 patients with $\mathrm{PPH}$ and eight with CTEPH. Mean SAP and mean DAP were elevated in both groups, although, in the PPH group, they were slightly higher. Mean $\mathrm{CO}$ was decreased in both groups. Mean PAP (PPH, n=19; CTEPH, $n=8$ ) as well as mean PVR (PPH, $n=15$, CTEPH, $n=8$ ) and RAP were greatly elevated in both groups, although, in the PPH group, this was more pronounced (table 2).

\section{Relationship between pulmonary and cardiovascular function}

$T \mathrm{~L}, \mathrm{CO}$ and its components and RAP were determined in 16 patients with $\mathrm{PPH}$ and seven patients with CTEPH. A negative correlation was found between $V_{\mathrm{c}}$ and RAP, both when $V_{\mathrm{c}}$ was expressed as a percentage of the predicted value (fig. 1) and when it was expressed in millilitres (fig. 2). No other significant correlations of $V_{c}$ with cardiovascular parameters were found. $D \mathrm{~m}$ was strongly associated with PVR, both when $D \mathrm{~m}$ was expressed as percentage of

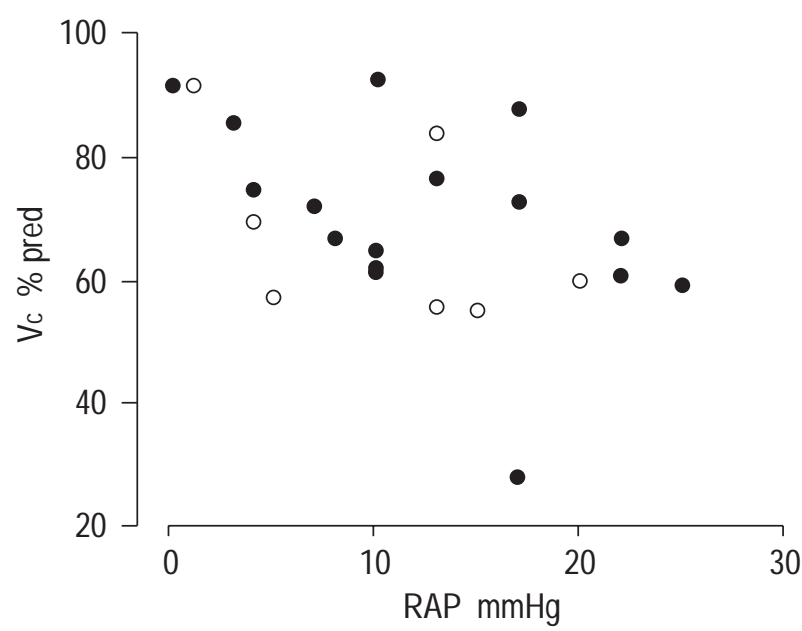

Fig. 1. - Correlation between mean right atrial pressure (RAP) and pulmonary capillary blood volume $\left(V_{\mathrm{c}}\right)$. $\mathbf{O}$ : primary pulmonary hypertension patients $(\mathrm{r}=-0.42, \mathrm{p}=0.10)$; $\bigcirc$ chronic thromboembolic pulmonary hypertension patients $(\mathrm{r}=-0.49, \mathrm{p}=0.26) .(1 \mathrm{mmHg}=0.133 \mathrm{kPa}$.

predicted value (fig. 3) and when it was expressed in $\mathrm{mmol} \cdot \mathrm{L}^{-1} \cdot \mathrm{kPa}^{-1}$ (fig. 4). For $D \mathrm{~m}$, too, no other significant correlations were observed.

\section{Discussion}

This study shows a reduced $T \mathrm{~L}, \mathrm{CO}$ and its two components, both in the PPH and the CTEPH groups. The reduction in $T \mathrm{~L}, \mathrm{CO}$ seems to be primarily caused by the decrease in $D \mathrm{~m}$, and to a lesser extent by the decrease in $V_{\mathrm{c}}$. Considering pulmonary and cardiovascular function values, no difference between the two groups could be established. A clear association between an increase in RAP and the

Table 2. - Static and dynamic lung volumes and haemodynamic parameters in patients with primary pulmonary hypertension (PPH) and chronic thromboembolic pulmonary hypertension (CTEPH)

\begin{tabular}{|c|c|c|c|c|}
\hline & \multicolumn{2}{|c|}{$\mathrm{PPH}$} & \multicolumn{2}{|c|}{ СТЕРН } \\
\hline & Mean \pm SD & $\%$ pred $\pm \mathrm{SD}$ & Mean \pm SD & $\%$ pred \pm SD \\
\hline Patients $n$ & \multicolumn{2}{|c|}{20} & \multicolumn{2}{|c|}{8} \\
\hline TLC L & $5.1 \pm 1.2$ & $93.0 \pm 17.9$ & $6.6 \pm 1.9$ & $94.5 \pm 11.0$ \\
\hline FEV1 L & $2.8 \pm 0.7$ & $88.4 \pm 20.1$ & $3.2 \pm 1.1$ & $83.0 \pm 14.6$ \\
\hline $\mathrm{FEV} 1 / \mathrm{VC} \%$ & $76.2 \pm 9.4$ & $96.3 \pm 12.4$ & $70.2 \pm 9.5$ & $87.9 \pm 9.8$ \\
\hline$T \mathrm{~L}, \mathrm{CO} \mathrm{mmol} \cdot \mathrm{min}^{-1} \cdot \mathrm{kPa}^{-1}$ & $6.0 \pm 1.46$ & $63.9 \pm 16.6$ & $7.68 \pm 3.36$ & $68.5 \pm 21.1$ \\
\hline KCO $\mathrm{mmol} \cdot \mathrm{min}^{-1} \cdot \mathrm{kPa}^{-1}$ & $1.24 \pm 0.30$ & $69.0 \pm 18.1$ & $1.15 \pm 0.21$ & $64.7 \pm 10.1$ \\
\hline$V_{\mathrm{c}} \mathrm{mL}$ & $48.9 \pm 9.03$ & $72.2 \pm 14.5$ & $62.24 \pm 22.5$ & $67.2 \pm 13.9$ \\
\hline$D \mathrm{~m} \mathrm{mmol} \cdot \mathrm{min}^{-1} \cdot \mathrm{kPa}^{-1}$ & $10.27 \pm 3.44$ & $59.6 \pm 22.5$ & $13.36 \pm 6.25$ & $66.8 \pm 24.5$ \\
\hline RAP mmHg & $12.3 \pm 7.2$ & - & $10.3 \pm 6.4$ & - \\
\hline $\mathrm{CO} \mathrm{L} \cdot \mathrm{min}^{-1}$ & $3.3 \pm 0.9$ & - & $3.7 \pm 0.8$ & - \\
\hline SAP mmHg & $101.2 \pm 27.0$ & - & $80.1 \pm 19.3$ & - \\
\hline DAP mmHg & $45.0 \pm 15.4$ & - & $35.9 \pm 12.7$ & - \\
\hline PAP mmHg & $68.2 \pm 19.4$ & - & $52.9 \pm 15.5$ & - \\
\hline PVR dyne $\cdot \mathrm{s} \cdot \mathrm{cm}^{-5}$ & $1244 \pm 558$ & - & $1097 \pm 422$ & - \\
\hline $\mathrm{CI} \mathrm{L} \cdot \mathrm{min}^{-1} \cdot \mathrm{m}^{-2}$ & $1.8 \pm 0.5$ & - & $1.9 \pm 0.3$ & - \\
\hline
\end{tabular}

$\%$ pred: percentage of the predicted value; TLC: total lung capacity; FEV1: forced expiratory volume in one second; VC: vital capacity; $T$ L,CO: transfer factor of the lung for carbon monoxide; $K \mathrm{CO}$ : transfer coefficient; $V$ c: pulmonary capillary blood volume; $D \mathrm{~m}$ : pulmonary membrane diffusion capacity; RAP: right atrial pressure; CO: cardiac output; SAP: systolic pulmonary artery pressure; DAP: diastolic pulmonary artery pressure; PAP: mean pulmonary arterial pressure; PVR: pulmonary vascular resistance; CI: cardiac index. No significant differences were found between patients in the PPH group and those in the CTEPH group. $(1 \mathrm{mmHg}=0.133 \mathrm{kPa}$.) 


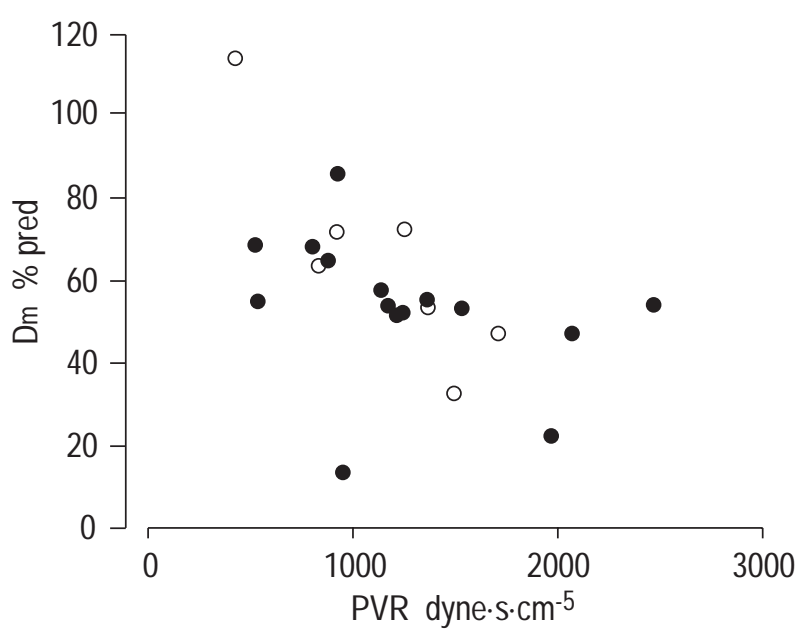

Fig. 2. - Correlation between pulmonary vascular resistance (PVR) and pulmonary membrane diffusion capacity $(D \mathrm{~m})$. 0 : primary pulmonary hypertension patients $(\mathrm{r}=-0.36, \mathrm{p}=0.20) ; \bigcirc$ chronic thromboembolic pulmonary hypertension patients $(\mathrm{r}=-0.87, \mathrm{p}=0.01)$.

decrease in $V_{\mathrm{c}}$ was found. An even stronger correlation between the decrease in $D \mathrm{~m}$ and the increase in PVR was observed.

The reduction in $T \mathrm{~L}, \mathrm{CO}$ found in this study is comparable to that observed in previous studies $[11,13]$. BorLAND et al. [23], in their study of 12 patients with $\mathrm{PPH}$, observed a significant reduction in $V$ c whereas the reduction in $D \mathrm{~m}$ did not reach statistical significance. The main differences, in the present study, were the greater female-to-male ratio and the larger number of patients in the PPH group. All other parameters except $V_{\mathrm{c}}$ and $D$ m were comparable. The reason for this may be the different method used to determine $D \mathrm{~m}$ and $V$ c. These authors measured simultaneously the single-breath uptake of carbon monoxide and nitric oxide. However, the values obtained in this way are not compatible with the method of Roughton and FORSTER [19] employed in the present study.

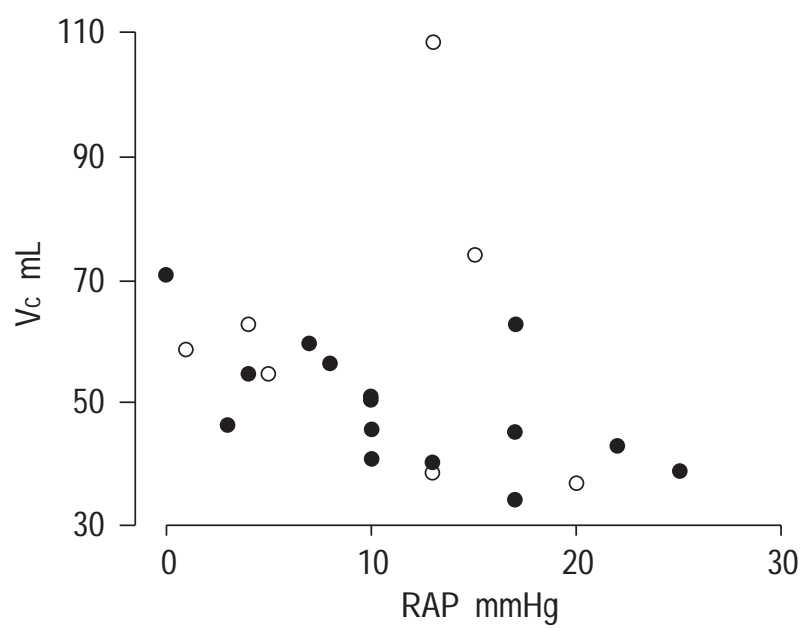

Fig. 3. - Association between mean right atrial pressure (RAP) and pulmonary capillary blood volume $(V \mathrm{c})$. $\mathrm{O}$ : primary pulmonary hypertension patients $(\rho=-0.64, p=0.06) ; \bigcirc$ chronic thromboembolic pulmonary hypertension patients $(\rho=-0.20, p=0.67) .(1 \mathrm{mmHg}=0.133 \mathrm{kPa}$. $)$

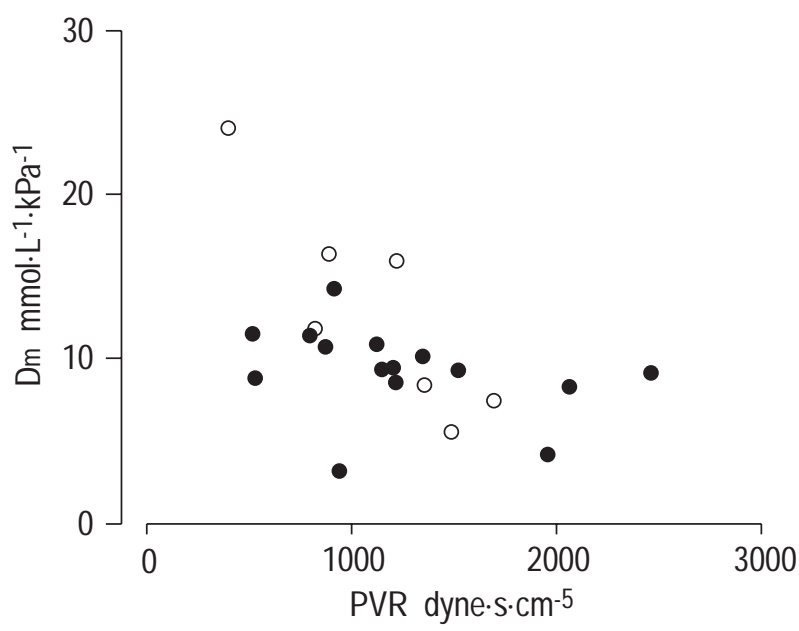

Fig. 4. - Association between pulmonary vascular resistance (PVR) and pulmonary membrane diffusion capacity $(D \mathrm{~m})$. : primary pulmonary hypertension patients $(\rho=-0.54, p=0.038) ; \bigcirc$ chronic thromboembolic pulmonary hypertension patients $(\rho=-0.86, p=0.01)$.

The fact that no differences were found between the PPH and the CETPH group must be interpreted with caution. In descriptive studies, as presented here, it is not always possible to choose the optimum group sizes for avoiding a type II error. However, from the observed pulmonary function values and the number of patients, it is estimated that a difference of $20 \%$ pred would be detectable with a power of 0.8 and a significance level of 0.05 . The figures presented also show that the two hypertension groups cannot be discerned as separate entities. Therefore, in the authors' opinion, no differences of clinical importance exist between the two groups regarding physiological values. This is in contrast with other investigators who report that $T \mathrm{~L}, \mathrm{CO}$, in CTEPH patients, is often in the normal range [24]. This is postulated to be due to backperfusion of the capillary bed by the extensive bronchial arterial collateral flow. In that case, the $V_{\mathrm{c}}$ as determined by carbon monoxide uptake should be near normal. The present results, however, provide no evidence for such a theory.

The reduced $V_{\mathrm{c}}$ in $\mathrm{PPH}$ as well as in CTEPH may result from the obstruction and obliteration of arterioles caused by medial hypertrophy and intimal fibrosis $[7,15]$ or by the resulting plexogenic lesions which can be considered as nonfunctional parallel capillaries. An inverse relation was found between mean RAP and $V_{\mathrm{c}}$, indicating decreasing $V_{\mathrm{c}}$ with increasing pulmonary hypertension. The inverse association of mean RAP and $V_{\mathrm{c}}$ may be partly explained by alterations in haemodynamics: with increasing right ventricular failure mean RAP is increased. Consequently, a shift of the blood volume in the lung in the direction of the right heart occurs and $V_{\mathrm{c}}$ decreases. No association between mean RAP and Dm was found, suggesting that the severity of pulmonary hypertension, often indicated by the elevated mean RAP, does not completely explain the reduction in $T \mathrm{~L}, \mathrm{CO}$.

The reduction in $D$ m indicates that the capillary bed in the lung is also involved. This decrease can be explained by the increase in alveolocapillary membrane thickness, possibly caused by the proliferation of monoclonal 
endothelial cells $[5,15]$. The proliferation of monoclonal endothelial cells at a capillary level leads to thickening of the capillary wall and thus a decrease in $D \mathrm{~m}$. With increasing proliferation, ultimately resulting in obliteration of arterioles [16], vascular resistance increases. This may be an explanation for the observed correlation between the increase in PVR and the decrease in $D \mathrm{~m}$. Another factor could be the presence of interstitial oedema. If this were the only factor, it would be hard to explain the association of $D \mathrm{~m}$ with PVR: PVR would then be determined almost completely by the capillary bed, which is unlikely. Assayag et al. [25] found a similar association of $D \mathrm{~m}$ and PVR in patients with chronic left cardiac disease, independent of the degree of pulmonary congestion. This may also be an indication that the influence of oedema is limited. The observed correlation suggests that $D \mathrm{~m}$ is a sensitive marker of increased PVR.

Frequently, the main vascular lesion in PPH is considered to be at the precapillary level, whereas CTEPH is a large-vessel disease. Both views could explain the reduction in $D \mathrm{~m}$ as a result of loss in functional capillary exchange surface area. However, in that case, alveolar volume would be decreased, which was not observed in this study. Moreover, marked thickening of the alveolar wall has been demonstrated in electron microscopic studies in patients with PPH [26] and in a case of pulmonary veno-occlusive disease [27]. This is another indication that disturbances occur at the blood/gas barrier which are very compatible with the decrease in $D$ m reported in the present study.

In summary, in patients with primary pulmonary hypertension and chronic thromboembolic pulmonary hypertension, a reduction in both pulmonary capillary blood volume and the diffusing capacity of the alveolocapillary membrane have been observed. The decrease in pulmonary capillary blood volume was associated with an increase in right atrial pressure, probably caused by altered haemodynamic conditions. The large reduction in pulmonary membrane diffusion capacity suggests pronounced functional impairment of the alveolocapillary membrane in the pathophysiology of primary pulmonary hypertension and chronic thromboembolic pulmonary hypertension. Pulmonary membrane diffusion capacity may be a sensitive indicator for increased pulmonary vascular resistance in these patients. This may be of clinical importance. The severity of pulmonary hypertension is determined mainly by haemodynamic parameters such as right atrial pressure and pulmonary vascular resistance, both parameters which can be determined by right heart catheterization. This is not an easy means of monitoring the progression of the disease. Although the present study is cross-sectional in design, it may be an indication that monitoring the progression of pulmonary hypertension could be performed by measuring the transfer factor for carbon monoxide and its components, a simple patient-friendly procedure that can be performed repeatedly.

\section{References}

1. Rubin LJ. Primary pulmonary hypertension. $N$ Engl $J$ Med 1997; 336: 111-117.

2. Tillman O, Speich R. Die primaire pulmonale Hypertonie. Klinik Verlauf und prognostische Faktoren. [Abstract in English]. Schweiz Med Wochenschr 1997; 127: 923-934.
3. Rich S. Primary pulmonary hypertension. Prog Cardiovasc Dis 1988; 31: 205-238.

4. Wagenvoort CA. Pulmonale hypertensie. Pathologie van de pulmonale hypertensie. In: Sluiter HJ, Demedts M, Dijkman JH, Hilvering C, eds. Longziekten. Assen, Maastricht, Van Gorcum, 1993; pp. 677-685.

5. Tuder RM, Groves B, Badesch DB, Voelkel NF. Exuberant endothelial cell growth and elements of inflammation are present in plexiform lesions of pulmonary hypertension. Am J Pathol 1994; 144: 275-285.

6. Bjornsson J, Edwards WD. Primary pulmonary hypertension: a histopathologic study of 80 cases. Mayo Clin Proc 1985; 60: 16-25.

7. Moser KM, Bloor CM. Pulmonary vascular lesions occurring in patients with chronic major vessel thromboembolic pulmonary hypertension. Chest 1993; 103: 685-692.

8. D'Alonzo GE, Barst RJ, Ayres SM, et al. Survival in patients with primary pulmonary hypertension: results from a national prospective registry. Ann Intern Med 1991; 115: 343-349.

9. Sandoval J, Bauerle O, Palomar A, et al. Survival in primary pulmonary hypertension. Validation of a prognostic equation. Circulation 1994; 89: 1733-1744.

10. Rich S, Dantzker DR, Ayres SM, et al. Primary pulmonary hypertension: a national prospective study. Ann Intern Med 1987; 107: 216-223.

11. Burke CM, Glanville AR, Morris AJR, et al. Pulmonary function in advanced pulmonary hypertension. Thorax 1987; 42: 131-135.

12. Moser KM, Auger WR, Fedullo PF. Chronic, major vessel thromboembolic pulmonary hypertension. Circulation 1990; 81: 1735-1743.

13. Bernstein RJ, Ford RL, Clausen JL, Moser KM. Membrane diffusion and capillary blood volume in chronic thromboembolic pulmonary hypertension. Chest 1996; 110: 1430-1436.

14. Anderson EG, Simon G, Reid L. Primary and thromboembolic pulmonary hypertension: a quantitative pathological study. J Pathol 1973; 110: 273-293.

15. Lee S-D, Shroyer KR, Markham NE, Cool CD, Voelkel NF, Tuder RM. Monoclonal endothelial cell proliferation is present in primary but not secondary pulmonary hypertension. J Clin Invest 1998; 101: 927-934.

16. Voelkel NF, Tuder RM. Cellular and molecular mechanisms in the pathogenesis of severe pulmonary hypertension. Eur Respir J 1995; 8: 2129-2138.

17. Quanjer $\mathrm{PhH}$, Tammeling GJ, Cotes JE, Pedersen OF, Peslin R, Yernault J-C. Lung volumes and forced ventilatory flows. Report working party standardization of lung function tests European Community for Steel and Coal. Eur Respir J 1993; 6: Suppl. 16, 5-40.

18. Cotes JE. Lung Function, 4th Edn. Oxford, Blackwell Scientific Publications, 1979.

19. Roughton FJW, Forster RE. Relative importance of diffusion and chemical reactions rates in determining the exchange of gases in the human lung with special reference to the true diffusion capacity of pulmonary membrane and volume of blood in the lung capillaries. $J \mathrm{Appl}$ Physiol 1957; 11: 290-302.

20. Luursema PB, Star-Kroesen MA, van der Mark ThW, et al. Bleomycin-induced changes in the carbon monoxide transfer factor of the lung and its components. Am Rev Respir Dis 1983; 128: 880-883.

21. Groen H, Wichers G, Ter Borg EJ, Van der Mark ThW, Wouda AA, Kallenberg CGM. Pulmonary diffusion capacity disturbances are related to nailfold capillary changes 
in patients with Raynaud's phenomenom with and without an underlying connective tissue disease. Am J Med 1990; 89: $34-41$.

22. Groen HJM, van der Mark ThW, van der Leest AHD, De Vries EGE, Mulder NH. Pulmonary function changes in lung cancer patients treated with radiation with or without carboplatin. Am J Respir Crit Care Med 1995; 152: 20442048.

23. Borland C, Cox Y, Higenbottam T. Reduction of pulmonary capillary blood volume in patients with severe unexplained pulmonary hypertension. Thorax 1996; 51: $855-856$.
24. Moser KM, Auger WR, Fedullo PF, Jamieson SW. Chronic thromboembolic hypertension: clinical picture and surgical treatment. Eur Respir J 1992; 5: 334-342.

25. Assayag P, Benamer H, Aubry P, et al. Alteration of the alveolar-capillary membrane diffusing capacity in chronic left heart disease. Am J Cardiol 1998; 82: 459-464.

26. Villaschi S, Pietra GG. Alveolo-capillary membrane in primary pulmonary hypertension. Appl Pathol 1986; 4: 132-137.

27. Kay JM, de Sa DJ, Mancer JF. Ultrastucture of lung in pulmonary veno-occlusive disease. Hum Pathol 1983; 14: $451-456$. 